\title{
The effect of orienting tasks on recognition memory
}

\author{
ELIZABETH K. WARRINGTON and CAROL ACKROYD* \\ National Hospital, Queen Square, London, W. C. 1.
}

\begin{abstract}
The effect of orienting tasks on recognition memory for words and faces was investigated. It was found that relevant orienting tasks improved recognition memory for both classes of stimuli compared with a nonrelevant orienting task and the control condition of testing recognition memory without an orienting task. Attention is drawn to the possibility of qualitative differences between recall and recognition for the effect of orienting tasks. The findings are related to recognition theories. It is suggested that the findings lend support to those theories which hold that retrieval processes play a major role in recognition memory.
\end{abstract}

It is well established that performance on a recall task is a function of the nature of orienting tasks. Recall following semantic orienting tasks is as good as recall without such a task and is superior to recall following nonsemantic orienting tasks (Hyde \& Jenkins, 1969, 1973; Johnston \& Jenkins, 1971). Furthermore, the effect of such orienting tasks applies equally under conditions of incidental and intentional learning (Eagle \& Leiter, 1964; Hyde \& Jenkins, 1969, 1973). This difference between semantic and nonsemantic orienting tasks for recall performance has been the subject of detailed analysis. It has been argued that neither time, effort, nor stimulus fractionation can account for the effects of these orienting tasks (Hyde, 1973; Walsh \& Jenkins, 1973; Johnston \& Jenkins, 1971). Jenkins and his colleagues have rejected an interpretation suggested by Mechanic (1962) in terms of response at time of learning in favor of a processing hypothesis. By requiring the $S$ to process the semantic features of the stimulus items, namely words, it is held that the $\mathrm{S}$ can use these meaningful associations as an aid to organize his recall. It is important to note that the absence of any difference between intentional learning with a semantic orienting task and without an orienting task has received little comment.

The effects of orienting tasks have only been investigated for the retention of verbal material. It is, therefore, of interest to establish whether this phenomenon is a property of retention of other classes of information. The present study was undertaken to investigate the effect of orienting tasks for retention of one class of meaningful nonverbal material-faces; a recognition rather than a recall paradigm was thus necessitated, and a comparable verbal task was included for comparison.

\section{METHOD}

\section{Test Stimuli}

Forced-chuice recognition memory for words and faces was tested using three instruction conditions. Identical iest stimuli

*We wish to thank T. Shallice and R. T. C Pratt for their advice in the preparation of this manuscript. Carol Ackroyd was supported by a grant from the Medical R esearch Council. were used for each of the three conditions. The word stimuli were 50 high-frequency (A and AA Thorndike-Lorge) 4-5 letter words, and 50 distractor items drawn from the same pool. Similarly the faces' stimuli were 50 black/white photographs of unknown male actors (Spotlight Magazine) and 50 distractor items drawn from the same pool. The actors were judged to be unknown if not recognized by any member of the psychology department. The word stimuli were printed individually on cards, and for forced-choice recognition all the stimulus words, each paired with a distractor item, were printed on a single sheet of paper, the S being required to "mark" each stimulus item. The face stimuli $(3 \times 4$ in.) were mounted on white cards ( $4 \times 6$ in.) and in the recognition task pairs of faces (a stimulus item and a distractor item) were presented together and the $\mathrm{S}$ was required to "point" to the stimulus item.

\section{Procedure}

Three instruction conditions were used for each class of test stimulus, words and faces. Relevant and nonrelevant semantic orienting tasks were preferred since they differ in fewer dimensions than the semantic and nonsemantic orienting tasks used in previous studies. This procedure ensures that the whole stimulus is attended to and in each case the possibility of forming associations is present. (1) No Orienting Task: The Ss were merely instructed to attend to each stimulus item and toid that retention would be tested. (2) Relevant Orienting Task: In addition to being told that retention would be tested, Ss were required to categorize each stimulus item as pleasant or unpleasant. This instruction was identical for the word and face stimuli. (3) Nonrelevant Orienting Task: In addition to being told that retention would be tested Ss were required to categorize each word stimulus as green or red and in the case of the face stimuli as tall or short.

Both the 50-word and the 50-face stimuli were presented to the $S$, timed by a stopwatch, at approximately a 3-sec rate. In the relevant and nonrelevant orienting conditions the $S$ was required to respond during the $3 \mathrm{sec}$ and before the presentation of the next stimulus item. The presentation order of the test items was constant across Ss. A different but constant order of items was used for the retention test. The retention test was not paced, and the approximate duration of each test session was 5-6 $\mathrm{min}$.

\footnotetext{
Subjects

Friends and relations of patients attending the out-patient department of the National Hospital, aged between 50 and 70 years, tested individually, and sitting at a table in a crowded out-patient department, were the Ss of this experiment. Independent groups of 20 Ss were tested and allotted randomly to one of the six conditions of the experiment. The mean age in each of the six groups was very similar and none of the minor differences in mean age were significant.
} 
Table 1

Mean Error Scores and Standard Deviations for Word and Face Stimuli for Each Recognition Task

\begin{tabular}{|c|c|c|c|c|c|c|}
\hline & \multicolumn{6}{|c|}{ Orienting Task } \\
\hline & \multicolumn{2}{|c|}{ None } & \multicolumn{2}{|c|}{ Relevant } & \multicolumn{2}{|c|}{ Nonrelevan } \\
\hline & Mean & $\mathrm{SD}$ & Mean & $\mathrm{SD}$ & Mean & SD \\
\hline Words & 12.60 & 4.89 & 4.75 & 5.71 & 9.90 & 5.76 \\
\hline Faces & 11.10 & 3.91 & 7.00 & 3.04 & 10.00 & 3.49 \\
\hline
\end{tabular}

\section{RESULTS}

The mean error score and the standard deviation for each of the six conditions are given in Table 1. A one-way analysis of variance was computed for the three conditions using word stimuli $(\mathrm{F}=10.6$, $\mathrm{df}=2.57$, $\mathrm{p}<.01$ ), indicating that for both classes of stimuli the instructional condition was a significant variable. The Newman-Keuls test was, therefore, applied to the mean error scores for each condition; the values of " $q$ " and levels of significance are given in Table 2. For both faces and words there is a clear-cut improvement in performance on the relevant orienting task condition compared with both the no orienting task condition and the nonrelevant orienting task condition. In neither case was there any significant difference between the no orienting task condition and the nonrelevant orienting task condition.

\section{DISCUSSION}

The present investigation extends the generality of previous investigations by showing that orienting tasks affect retention when tested by forced-choice recognition and that these effects are not restricted to word stimuli but in addition affect retention of one class of nonverbal meaningful stimuli, namely faces. The two types of orienting tasks devised for this study were very similar insofar as they differed only in semantic relevance to the stimulus material to be retained, yet a clear-cut superiority of the relevant orienting task over the nonrelevant orienting task for recognition memory was found for both words and faces. Thus, no evidence for any material-specific differences in recognition memory has been found.

Two interrelated aspects of the present findings warrant further discussion. First, it would seem that there may be qualitative differences between recall and recognition when orienting tasks are, or are not, performed. Second, the present findings have implications for current theories of recognition.

There are a limited number of variables known to have a differential effect on recall and recognition memory, the most robust of which is word frequency (Hall, 1954; Shepard, 1967). Incidental and intentional learning instructions have reverse effects on retention tested by recall and recognition (Eagle \& Leiter, 1964;
Table 2

Results of Newman-Keuls Test Giving Values of $q$ and Level of Significance for Each Class of Stimuli

\begin{tabular}{lcccccc} 
& \multicolumn{2}{c}{$\begin{array}{c}\text { Face } \\
\text { Stimuli }\end{array}$} & & \multicolumn{2}{c}{$\begin{array}{c}\text { Word } \\
\text { Stimuli }\end{array}$} \\
\cline { 2 - 3 } \cline { 6 - 7 } & Judgment & $\mathrm{q}$ & $\mathrm{p}<$ & & $\mathrm{q}$ & $\mathrm{p}<$ \\
\hline Relevant vs None & 5.24 & .01 & & 5.28 & .001 \\
Irrelevant vs Relevant & 3.83 & .01 & & 3.48 & .05 \\
Irrelevant vs None & 1.60 & n.s. & & 1.81 & n.s. \\
\hline
\end{tabular}

Estes \& Da Polito, 1967). Elias and Perfetti (1973) have shown that semantic encoding instructions improve performance on a word recognition task, and the present study provides further evidence of this class of qualitative difference. Here, the relevant semantic orienting task (the pleasant/unpleasant judgment) which was identical to those used in previous studies, resulted in recognition memory superior to the control condition of no orienting task, a contrast to the findings with a recall measure where these two conditions have been shown repeatedly to yield identical recall scores, albeit with much younger student Ss.

However, the question remains, why should a semantic orienting task compared with no orienting task improve retention tested by recognition. The notion that recognition is mediated by an associative retrieval process (Anderson \& Bower, 1972) together with a consideration of the effects of cued recall suggest a tentative explanation. It is known that cued recall is superior to noncued recall (Tulving \& Pearlstone, 1966; Tulving \& Osler, 1968) and, furthermore, a close associate is more effective than a remote associate as a cue (Bahrick, 1970). In a recognition task, one could then argue that the $S$ treats the two-choice stimulus items as cues for associative retrieval, the probability of an item being correctly recognized increasing if an association to that item is achieved. The semantic orienting task (the pleasant/unpleasant judgment) could provide a relatively easily retrieved associate for the subsequent recognition task analogous to that provided by a close associate cue in a free recall task. Similarly, in the recognition task not preceded by a relevant semantic orienting task, there would be no easily retrieved associate available; then the stimulus item would provide a cue analogous to a remote associate cue in free recall.

A theory of recognition emphasizing strength or frequency cannot accommodate the present findings, which demonstrate that recognition memory can be manipulated by orienting tasks. However, the present findings do provide positive support for theories of recognition memory in which retrieval processes play a major role. Two variants of this theory have been put forward. On the one hand, Mandler et al (1969) have argued that recognized items are first subjected to a retrieval test and, on the other hand, Anderson and Bower (1972) stress that recognition is mediated by association to contextual elements. The findings of the 
present study are compatible with either formulation. In conclusion, it is tentatively suggested that in a recognition task a previously experienced stimulus item provides a retrieval cue which is more or less effective depending on the accessibility of mediating associations.

\section{REFERENCES}

Anderson, J, R, \& Bower, G. H. Recognition and retrieval processes in free recall. Psychological Review, 1972, 79, 97-123.

Bahrick, H. P. Two-phase model for prompted recall. Psychological Review, 1970, 77, 215-222.

Eagle, M. \& Leiter, E. Recall and recognition in intentional and incidental learning. Journal of Experimental Psychology, $1964,68,5863$.

Elias, C. S., \& Perfetti, C. A. Encoding task and recognition mem ory: the importance of semantic encoding. Journal of Experimental Psychology, 1973, 99, 151-156.

Estes, W. K., \& Da Polito, F. Independent variation of information storage and retrieval process in paired associate learning. Journal of Experimental Psychology, 1967, 75, 18-26.

Hall, J. F. Learning as a function of word frequency, American Journal of Psychology, 1954, 67, 138-140.

Hyde, T. S. The differential effects of effort and type of orienting task on the recall and organization of highly-associated words. Journal of Experimental Psychology, $1973,79,111-113$.

Hyde, T. S., \& Jenkins, J. J. Differential effects of incidental tasks on the organization of recall of a list of highly-assuciated words. Journal of Experimental Psychology, 1969, 82, 472-481.

Hyde, T. $\dot{S}$., \& Jenkins, J. J. Recall for words as a function of semantic graphic and syntactic orienting tasks. Journal of Verbal Learning \& Verbal Behavior, 1973, 12, 471-480.

Johnston, C. D., \& Jenkins, J. J. Two more incidental tasks that differentially affect associate clustering in recall. Journal of Experimental Psychology, 1971, 89, 92-95.

Mandler, G. Pearlstone, Z., \& Koopmans, H. S. The effects of organization and sem antic similarity on recall and recognition. Journal of Verbal Learning \& Verbal Behavior, 1969, 8, Ain.49.3

Mechanic, A. The responses involved in the rote learning of verbal materials. Journal of Verbal Learning \& Verbal Behavior, $1962,3,30-36$.

Shepard, R. N. R ecognition memory for words, sentences and pictures. Journal of Verbal Learning \& Verbal Behavior, 1967, 6, 156-163.

Tulving, E., \& Pearlstone, Z. Availability versus accessibility of information in memory for words. Journal of Verbal Learning \& Verbal Behavior, 1966, 5, 381-391.

Tulving, E. \& Osler, S. Effectiveness of retrieval cues in memory for words. Journal of Experimental Psychology, 1968, 77, 593-601.

Walsh, D. A. \& Jenkins, J. J. Effects of orienting tasks on free recall in incidental learning: "Difficulty," "Effort," and "Process" explanations. Journal of Verbal Learning \& Verbal Behavior, 1973, 12, 481-488.

(Received for publication March 25, 1974, revision received July $1,1974$. 